\title{
Innovative Research and Practice of REPE Class Teaching Mode on Integrated English Course in Application-Oriented University
}

\author{
Ming Cao \\ School of Humanities and International Education \\ Peihua University \\ Xi'an, China
}

\begin{abstract}
Based on characteristics of applied talents cultivation in application-oriented university, the purpose of present study is to improve students English language ability (ELA). It rebuilt the curriculum of integrated English course and developed a model of REPE (reconstruction + e-platform + process evaluation). To investigate the effectiveness of this model, both qualitative and qualitative methods have been used. 69 students as an experimental group and 68 as a control group, by random sampled, have participated this quasi-experiment. After one and half years of in-class implementation, experimental group has obtained better performance than control group in CET (College English Test). T-test shows significant differences in the result of CET total score $(p=0.042<0.05)$ and listening $(p=0.008<0.05)$ as well as writing $(\mathrm{p}=0.022<0.05)$ section score. These results suggest that REPE model is an effective model to enhance students ELA.
\end{abstract}

Keywords-REPE mode; Application-oriented university; Integrated English; ELA

\section{INTRODUCTION}

Application-oriented university usually refers to a kind of higher education institutes categorized to cultivate qualified graduates with hands-on experience, technical ability and practical skills for regional economy and all walks of life ${ }^{[1]}$. It has characteristics of career orientation. According to education classification of UNESCO, Application-oriented university belongs to the level 5A2, corresponding to research-based education ${ }^{[2,3]}$. Targeting to application and specific occupation needs, these universities provide ability of applying knowledge and skills so that the curriculum has a great difference from research-based education. It emphasizes the ability of implementation of the theory, with a lot of activities and practice. Integrated English is a compulsory course in fundamental stage of English major students who acquire basic language communicative skills by attending a variety of language activities to reach the requirement of the curriculum, including listening, speaking, reading, writing, and translating. For years, many teachers stick to the idea of propagating the doctrine, imparting professional knowledge, and resolving doubts. They pay attention to impart the knowledge but neglect students learning autonomy. They often take care of the top students in the class and forget the underachievers. This inevitably brings inequity in class learning and deviates the principle of student-centered school education. As for application-oriented university, it is urgent to change the teaching concept, and explore an effective and suit to their own development to cultivate graduates who not only have the ability of language skills, but also bear the features of creative mind, being prepared to cooperate with others, having the spirit of inquiry, and higher humanistic quality to serve the local economy.

\section{THEORETICAL BASIS}

Constructivism is the leading theory of current education reform. It mainly includes how to understand knowledge and learning. It proposes that leaning and knowledge acquisition is an active interaction and constant construction process between learners and environment. Learning first mediates on the psychological level between the learner and the teacher. Knowledge comes into learners mind through participation in the process of interpersonal interaction called "internalization". Only teachers and students strive hard to work together, can they both move further ${ }^{[4]}$. Not only is knowledge delivered to the students as a whole, but students are also the participators during construction of meanings. A constructivist's task is to design an experiential setting, scaffolding, and joining their cooperation to offer a chance to develop their own understanding for outside world ${ }^{[5]}$. Hence, learning is a process to realize knowledge enlargement under the influence of four key factors, such as specific situation, collaboration, communication, and meaning construction. It is a process to realize to enlarge knowledge; construtivsm emphasizes student-centered so that students are the subjects to process the information and the constructor of knowledge; students are neither machine to accept language information passively, nor the objects by feeding. Therefore, teachers need to change their roles from a propagator and inculcator to a promoter and facilitator ${ }^{[6]}$. Based on the theory of constructivsm, this paper is intended to set up an a studentcentered learning environment, to create a useful teaching and learning mode to fit applicationoriented university study, and to increase students' English ability by adopting e-platform as well. 


\section{TEACHING MODE}

Teaching mode can be summed up in the format of "reconstruction+e-platform+process evaluation" (REPE).

\section{A. Reconstruction}

Textbook is just one kind of material for students. It stresses logical reasoning and scientific way of thinking. The research precursors' rigorous and condensed conclusions in lines make the contents hard to understand. This leads to the result that teachers need to decode the principles, concepts and difficult points to fit student level. As a result, based on the original source of the textbook, we rearranged the contents by adding hands-on related materials, deleting and omitting simplified and sophisticated topics, and modifying some typical contents. We combined different ways of teaching and learning, such as topic research, project activities, role-play, vocabulary practice, discussion, presentation, debate and other format of activities. It converts teacher-centered

style,

which

is

"vocabulary-text-grammar-exercise" to the language practicing way of learning with different blocks representing different goals (See figure 1). This is the so called reconstruction. Since learning starts from questions and interests, students are motivated. As a result, knowledge internalization can be realized at the same time.

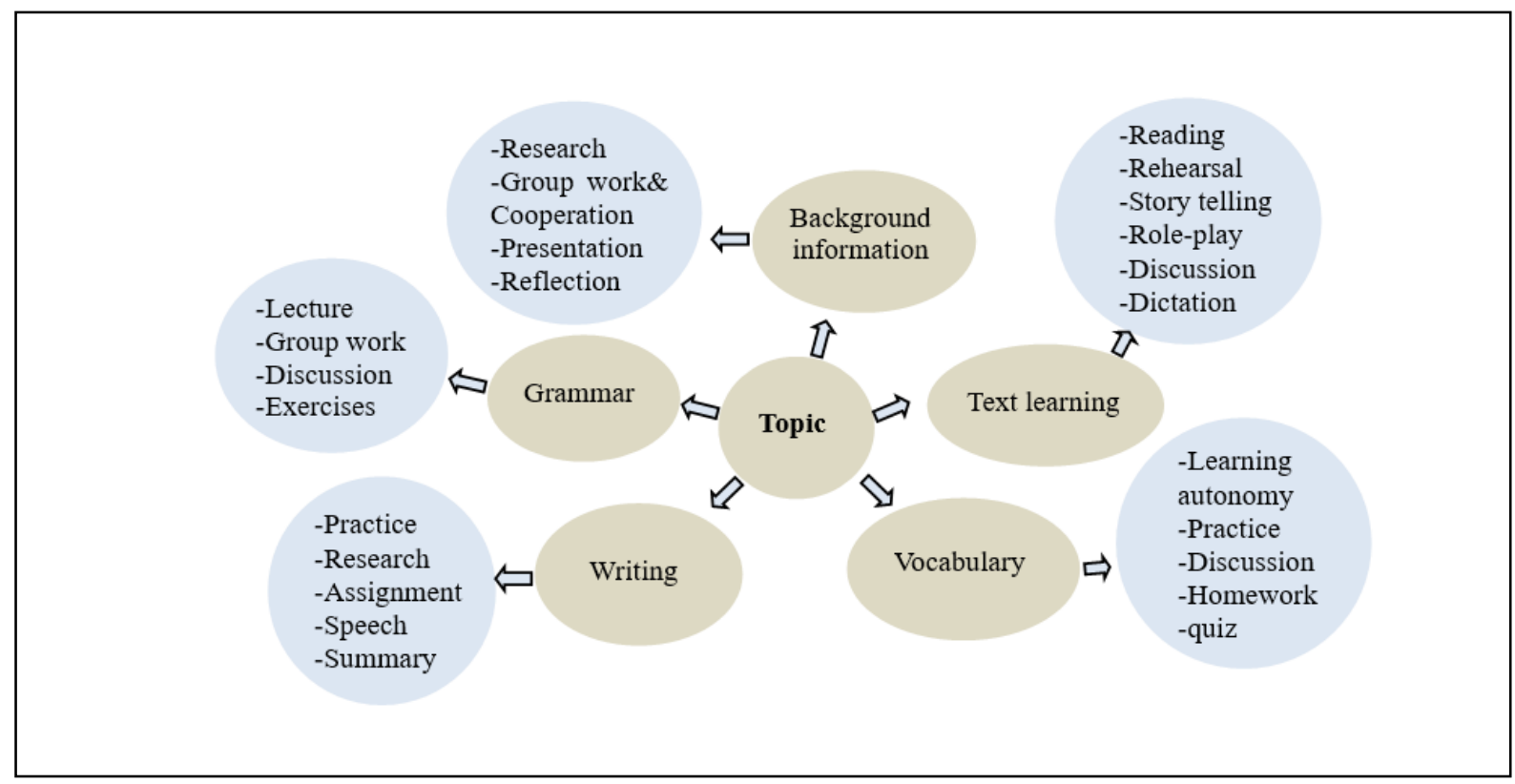

Fig. 1 An example of text material reconstruction

\section{B. E-platform}

E-platform is powerful due to its flexibility and the capacity to store large amount of resources. We use this platform to upload lecture PPT, guidance of learning, study materials, discussion questions, assignment samples and any other useful resources for students. Assignments can also be uploaded by this platform and online discussion is a popular way of after-class learning. Students can use these materials to preview and review to achieve knowledge internalization. Consequently, this e-platform becomes potable tools and makes learning more effectively.

\section{Process evaluation}

Process evaluation can be used as a real time monitor to reflect students' current study status on their way to reach the goals. It can quickly reflect where they are, what current strengths or weakness they have, and how they can reach the goals, etc. By reviewing the process evaluation tools, teachers and students can work together to discuss the problems, find out strategies, and overcome the difficulties to reach the final goals - to internalize the knowledge. The learning task has been divided into different blocks and every block has its own evaluation rubrics for measuring. All the items gather together to form one table in order to measure attendant rates, group work and cooperation including in-class and after-class cooperative study, the result of assignment, vocabulary study, language application and so on. Every block accounts for certain percentage of the total marks which accumulate to 100 percentage (See table I. By doing this, students understand 
their tasks and goals well and teachers also know how to help

students to make progress.

TABLE I RECORD OF PROCESS EVALUATION

\begin{tabular}{|c|c|c|c|c|c|c|c|c|c|c|c|c|c|c|c|c|c|c|c|c|c|c|c|c|}
\hline \multirow{2}{*}{\multicolumn{3}{|c|}{$\begin{array}{c}\text { Student } \\
\text { Information } \\
\text { Item \&Date }\end{array}$}} & \multirow{2}{*}{\multicolumn{3}{|c|}{$\begin{array}{c}\text { Attendance } \\
10 \%\end{array}$}} & \multicolumn{6}{|c|}{ Cooperative Study $30 \%$} & \multirow{2}{*}{\multicolumn{4}{|c|}{$\begin{array}{l}\text { Assignment } \\
15 \%\end{array}$}} & \multirow{2}{*}{\multicolumn{5}{|c|}{$\begin{array}{c}\text { Vocabulary } \\
20 \%\end{array}$}} & \multirow{2}{*}{\multicolumn{3}{|c|}{$\begin{array}{l}\text { Language Application } \\
\qquad 25 \%\end{array}$}} & \multirow{4}{*}{$\begin{array}{c}\text { Total } \\
100\end{array}$} \\
\hline & & & & & & \multicolumn{4}{|c|}{$\begin{array}{l}\text { In-class } \\
20 \% \\
\end{array}$} & \multirow[t]{2}{*}{$\begin{array}{c}\text { After-class } \\
10 \%\end{array}$} & \multirow{3}{*}{ Sum } & & & & & & & & & & & & & \\
\hline \multirow{2}{*}{ No } & \multirow{2}{*}{$\begin{array}{l}\text { Student } \\
\text { Number }\end{array}$} & \multirow{2}{*}{ Name } & & & \multirow{2}{*}{ Sum } & & & & & & & & & & & & & & & & Essay & Perform & Point & \\
\hline & & & 1 & $2=10$ & & 1 & 2 & 3 & 4 & 5 & & 1 & 2 & 3 & sum & 1 & 2 & 3 & 4 & Sum & 5 & $\begin{array}{l}\text {-ance } \\
10\end{array}$ & 10 & \\
\hline 1 & & & & $\therefore$ & & & & & & & & & & & & & & & & & & & & \\
\hline 2 & & & & 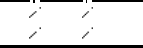 & & & & & & & & & & & & & & & & & & & & \\
\hline
\end{tabular}

\section{RESULTS}

A quasi-experiment has been implied in this research. 69 students as an experimental group and 68 as a control group, by random sampled, have participated this quasi-experiment. We used REPE mode for one and half years in class teaching. Here are quantitative and qualitative results and analysis.

\section{A. Quantitative analysis}

We took College English Test (CET result as an example to analyze students' achievement. Students attended CET voluntarily. Within 57 testers, $45.6 \%$ students from experimental group passed the examination, while $30.3 \%$ students from control group passed (See table II) Experimental group shows better performance in total grade as well as in sections of listening and writing. Reading score has a close similarity between two groups. T-test shows significant differences in the result of CET total grade $(\mathrm{p}=0.042<0.05)$ and other two sections of listening $(p=0.008<0.05)$ and $\operatorname{writing}(\mathrm{p}=0.022<0.05) \quad$ (See Table III).

TABLE II

CONTRAST TABLE

\begin{tabular}{|l|c|c|c|c|c|c|}
\hline \multirow{2}{*}{} & \multicolumn{3}{|c|}{ Experimental group } & \multicolumn{3}{c|}{ Control group } \\
\cline { 2 - 7 } & Numbers attended & Numbers passed & Passing rate & Numbers attended & $\begin{array}{c}\text { Numbers } \\
\text { passed }\end{array}$ & Passing rate \\
\hline Results & 57 & 26 & $45.6 \%$ & 66 & 21 & $30.3 \%$ \\
\hline
\end{tabular}

TABLE III STATISTICS OF SEPERATE ITEMS

\begin{tabular}{|l|l|r|r|r|r|}
\hline & \multicolumn{1}{|c|}{ Group } & Number & Mean & Standard deviation & Standard error of Mean \\
\hline \multirow{2}{*}{ Listening } & Experimental group & 57 & 138.95 & 25.141 & 3.330 \\
& Control group & 66 & 125.47 & 29.544 & 3.637 \\
\multirow{5}{*}{ Reading } & Experimental group & 57 & 142.05 & 21.400 & 2.834 \\
& Control group & 66 & 143.76 & 22.714 & 2.796 \\
& Experimental group & 57 & 136.02 & 14.135 & 1.872 \\
Writing & Control group & 66 & 130.42 & 12.565 & 1.547 \\
& Experimental group & 57 & 417.02 & 43.727 & 5.792 \\
& Control group & 66 & 399.65 & 49.085 & 6.042 \\
\end{tabular}




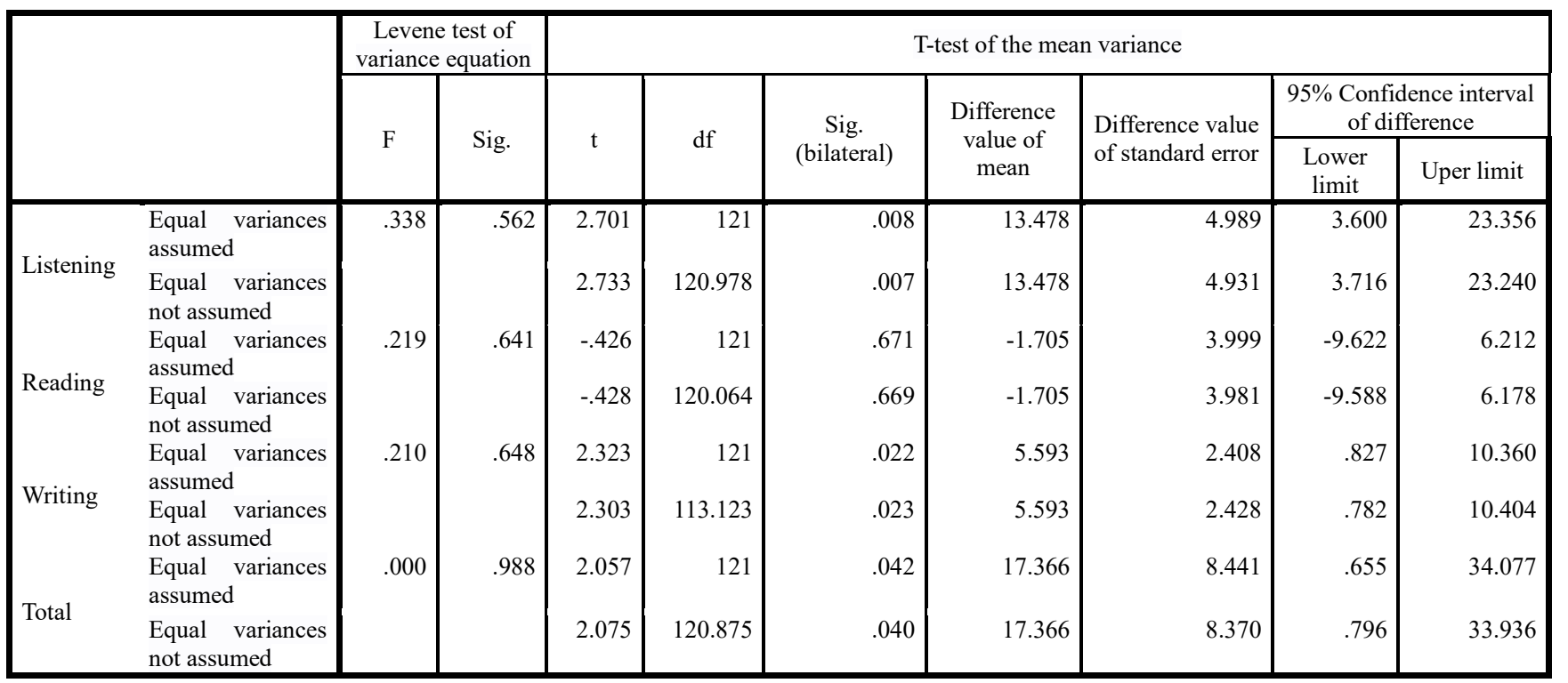

Significance level: 0.05

Experimental group has got better results than control group, which demonstrates the effectiveness of REPE mode. Writing is a kind of language output activity and students have gained significant improvements in classroom. Students are required to finish a summary after their group presentation in order to reflect their shortages and strengths so that they can find out whether they have learned something, how they cooperate with each other, how they allocate their task load, and what their future learning directions are. To express their ideas they need to make clear their mind and write down what they think. This is a very good way for them to improve their writing skills. For listening part, though it belongs to in-put category, in-class communication is a good way to improve listening skills. Teachers set a good example by interacting with students. If anyone makes any mistakes during conversation, teachers and peers can immediately recognize and correct them. This build up a very good foundation of pronunciation. As good pronunciation will bring good listening sense, students can easily understand the listening materials from a foreign speakers. It is hard to imagine that one can understand a standard English with a lot of pronunciation problems. This is just counteraction effect of frequent communication and interaction in class teaching.

\section{B. Qualitative analysis}

Qualitative research primarily involved personal interviews with students and their instructors. The consensus among students is that significant differences exists between the teaching methodology used this semester and traditional teaching methodologies, in which the students are motivated to learn; students spent more time not only on their own study but on group discussion and communication. They liked this kind of learning because, compared with traditional way of learning, they learned in a more flexible way; some students stressed that they had more chances to express their ideas and communicate with the teacher. This method activated them to study autonomously, encouraged them to search more information, and motivated them to try new technologies, such as PPT making; students cooperated more with each other and talked with each other in English which made them fearless to speak English in front of people; a lot of ways to evaluate their study in process, rubric[7] particularly, made them understand where they need to spend more time and how they could achieve the goal. As a result, in order to achieve a higher score, they need to research and study the rubrics very well. Even though the teacher's workload has been clearly increased, the students have more interaction in class and respond the teacher more frequently. They were eager to ask questions in the class and tried to find answers in different ways. Although teachers turned to be busy under these teaching mode in that they need to prepare for different kind of questions, upload documents, search materials, etc., it provides a good opportunity for teachers to convert themselves into a student-centered teacher and improve their abilities.

\section{CONCLUSION}

Although REPE teaching mode has been implemented for only one and half years, it has gained preliminary achievements: the view of teaching and learning has been changed and TEC score has improved. It further verified the feasibility of this mode. Since "learning while doing" is one of the basic principles in constructivism, for students from application-oriented university, the more chances they have to exhibit themselves, the higher confidence they will achieve, and the closer to the workplace they will be. To sum up, this paper introduces the teaching mode of REPE. First, it describes a serious methods we have used, especially in-class and after-class cooperation, presentation, performance, reflection, etc. Second, with the help of e-platform, students got more chances to collect learning materials and communication became much easier. Third, process evaluation has been implemented and rubrics have been creatively used to assess students progress. At the same time, 
it promotes teachers to convert their views from the traditional to the modern and to make their roles change from teacher-centered to student-centered. Nevertheless, we have a long way to go to improve this mode and to verify the effectiveness for student-centered learning.

\section{ACKNOWLEDGMENT}

\section{Research Projects}

2017 Higher Education Science Project from Shaanxi Association of Higher Education "Research on Countermeasures of Improving English Output competence of students in Application-Oriented University Based on Context of Globalization", Project No.XGH17190; 2017 Specific Research Project of Education Department of Shaanxi Provincial Government "Action Research on Cultivating Mode of Judging Perceiving and Multimoding Thinking ability for College Students in Foreign Language", Project No. 17JK1046; 2017 Research Project of Education and Teaching Reform from Xi'an Peihua University “Innovative Research and Practice of Class Teaching Model on Integrated English Course in Application-oriented University

Project No. PHY1726; 2016 Integrated English Top-quality Course of Xi'an Peihua University.

About the author

Ming Cao, Female, from Xi'an City, graduated from Brock University in Canada and Shaanxi Normal University in Xi'an China, and abtained two Master Degrees of Education, one majoring in Teaching, Learning and Development, the other, Psychology. She is currently an associate professor working in School of Humanities and International Education of Xi'an Peihua University. Her research direction is English education and teaching methodology.

\section{REFERENCES}

[1] Lu Wu-xia, The concept shackle and its break through for the connection of higher vocational education and application-oriented undergraduate education, Journal of Higher Education, vol. 33, pp. 59-64, August 2012. (In Chinese)

[2] International Standard Classification of Education 2011, Montreal UNESCO Institute for 2013. http://max.book118.com/html/2017/0611/113592927.shtm.

[3] Lanxi2008, International Standard Classification of Education 2011, https://wenku.baidu.com/view/063e5d35a32d7375a4178026.html. (In Chinese)

[4] G. Dimitriadis, \&G. Kamberelis, Theory for Education, New York, NY: Routledge. 2006: 6-9.

[5] P. Hinchey, Chapter three: Rethinking what we know positivist and constructivist epistemology, Finding Freedom in the Classroom (Revised Edition). New York: Peter Lang. 2010, pp. 33-55.

[6] He Ke-kang, Teaching mode, teaching method and teaching design of constructivism, Journal of Beijing Normal University (Social Sciences), 1997(5), pp.74-81.(In Chinese)

[7] Cao Ming, Designing and practicing the rubrics in college English formative assessment, College English Teaching \& Research, 2018(4), pp.7-11. (In Chinese) 